\title{
Musculoskeletal Disorders in Patients with Diabetes Mellitus: A Cross-Sectional Study
}

\author{
A. Majjad $(D),{ }^{1}$ Y. Errahali, ${ }^{2}$ H. Toufik, ${ }^{1}$ J. H Djossou, ${ }^{1}$ M. A. Ghassem, ${ }^{1}$ \\ J. Kasouati, ${ }^{3}$ and A. El Maghraoui ${ }^{1}$ \\ ${ }^{1}$ Rheumatology Department, Mohammed V Military Academic Hospital, Faculty of Medicine and Pharmacy, \\ Mohammed V-Souissi University, Rabat, Morocco \\ ${ }^{2}$ Endocrinology Department, Mohammed V Military Academic Hospital, Faculty of Medicine and Pharmacy, \\ Mohammed V-Souissi University, Rabat, Morocco \\ ${ }^{3}$ Department of Statistics, Faculty of Medicine and Pharmacy, Mohammed V-Souissi University, Rabat, Morocco
}

Correspondence should be addressed to A. Majjad; drmajjad@gmail.com

Received 22 January 2018; Revised 11 April 2018; Accepted 17 May 2018; Published 19 June 2018

Academic Editor: Hironobu Ihn

Copyright (C) 2018 A. Majjad et al. This is an open access article distributed under the Creative Commons Attribution License, which permits unrestricted use, distribution, and reproduction in any medium, provided the original work is properly cited.

Introduction. A variety of musculoskeletal disorders (MS) have been associated with diabetes mellitus (DM). This study aimed at assessing the prevalence and associated factors of MS disorders in Moroccan diabetic patients. Methods. A cross-sectional study enrolled consecutive patients with DM. We recorded demographic features of patients and characteristics of DM. MS disorders and vascular complications were assessed by clinical examinations and investigations. Associated factors of MS disorders were assessed by univariate and multivariate analyses. Result. 376 subjects were included; $84.6 \%$ had type 2 DM. The participants' median age was 54 years [45-62]; $41 \%$ had one or more vascular complications. 34.4\% had one or more MS disorders. Osteoarthritis was present in $19.4 \%$ of patients. Hand disorders were seen in $14.4 \%$. Shoulder capsulitis was present in $12.5 \%$. Long duration of diabetes and dyslipidemia were associated with increased prevalence of hand abnormalities $(P=0.017 ; P=0.019$, respectively). Age and dyslipidemia were associated with shoulder capsulitis $(P=0.019 ; P=0.047$, respectively). Female gender, overweight, and nephropathy were associated with increased odds of osteoarthritis $(P=0.009, P=0.004$, and $P=0.032$, respectively). Conclusion. MS disorders are frequent in this population and associated with various factors. HbAlc level does not appear to be associated with development of MS disorders.

\section{Introduction}

Diabetes mellitus (DM) is a major public health problem worldwide. It was estimated that in 2017 there are 451 million (age: 18-99 years) people with DM. These figures were expected to increase to 693 million by 2045 [1]. A variety of musculoskeletal (MS) disorders have been associated with $\mathrm{DM}$ and can cause significant disability $[2,3]$. These conditions include shoulder capsulitis (SC), limited joint mobility (LJM), trigger finger (TF), Dupuytren's contracture (DC), Charcot's foot (CF), carpel tunnel syndrome (CTS), osteoarthritis (OA), and other rare complications [4]. The pathophysiology leading to these disorders in patients with DM is not well understood. DM is a chronic metabolic disorder characterized by chronic hyperglycemia. High glucose levels may affect cell function and alter extracellular matrix components of the connective tissue producing damage [3, 5]. In contrast to vascular complications of DM, which has been studied extensively, MS disorders have been hitherto neglected. This study was carried out to investigate the prevalence of MS disorders in Moroccan diabetic patients, their associated factors, and their relationship to other diabetic complications, including micro- and macrovascular complications.

\section{Materials and Methods}

A cross-sectional study was performed between January 2015 and March 2016 and enrolled consecutive patients with 
type $1 \mathrm{DM}$ (T1DM) and type $2 \mathrm{DM}$ (T2DM) seen in the Endocrinology Department. Patients were included provided they had a history of DM for at least 1 year, diagnosed according to the World Health Organization as a fasting plasma glucose level of $\geq 126 \mathrm{mg} / \mathrm{dL}(7.0 \mathrm{mmol} / \mathrm{l})$ [6]. We excluded patients with a history of hand trauma, central or peripheral nervous system disease, chronic rheumatic disease, and end-stage renal disease and patients with thyroid disorders. Ethical approval was obtained from the local ethics committee.

For all patients included in the study, we recorded the following demographic features including age, gender, and body mass index (BMI). We obtained the following clinical information including type and duration of diabetes (in years), antidiabetic treatments, the hemoglobin A1C (HbAlc) levels of the patients, and lipid profile. Dyslipidemia was defined according to American Diabetes Association (ADA) criteria, 2008 [7]. Diabetes was considered controlled if HbAlc level was < 7\% according to ADA criteria, 2008 [7]. We also recorded vascular complications of DM, including microvascular complications (retinopathy, nephropathy, and neuropathy), and macrovascular complications (coronary artery disease, peripheral arterial disease, and history of stroke).

MS disorders were assessed using a targeted medical history, standardized physical examination, and investigations if needed. CTS was diagnosed based on clinical symptoms such as pain and sensory disturbances in the thumb, index, middle, and the outer half of the ring fingers and suspected cases were evaluated by electroneuromyography (ENMG). Diagnosis of SC was based on the limitation of active and passive shoulder joint movements in all directions, especially rotational movements. Limited joint mobility was evaluated by the patient "prayer sign". The diagnosis of DC was based on one or more of the following four features on examination: a palmar or digital nodule, tethering of the palmar or digital skin, a pretendinous band, and a digital flexion contracture. TF was diagnosed by palpating a nodule or thickened flexor tendon with locking happening in extension and flexion of any fingers. OA was researched on patients with chronic joint or back pain. The diagnosis was based on radiographic finding of reduced joint space, subchondral cyst, and osteophytes.

Descriptive statistics were obtained, such as mean values for continuous variables and proportions for categorical variables. The relation between prevalence of MS disorders and various variables was assessed for statistical significance using the Chi-square test. Multiple logistic regression analysis was conducted to assess the multivariate associations between MS disorders and different factors. A $P$-value $<0.05$ was considered statistically significant. Statistical analysis was carried out using the Statistical Package for Social Sciences (SPSS, version 23).

\section{Results}

3.1. Participant's Characteristics. The study included 376 DM patients. The participants' median age was 54 years [45-62].
There were as many men as women among the participants $(n=188$, sex ratio=1). 318 patients $(84.6 \%)$ had T2DM while $58(15.4 \%)$ had T1DM. The median duration of diabetes was 8 years [4-13]. Sixteen percent of our patients had more than 10 years of diabetes. $50.7 \%$ were treated with insulin \pm oral hypoglycemic. The mean HbAlc value was $8.5 \pm$ $2 \%$. Poor glycemic control was noted in $68.9 \%$ of patients. The mean BMI value was $26.4 \pm 3.6 \mathrm{~kg} / \mathrm{m}^{2} .45 .7 \%$ of the patients were overweight, while $15.4 \%$ were obese. In this study, 149 patients (39.6\%) had dyslipidemia and 155 (41\%) had one or more microvascular complications of diabetes. They were dominated by retinopathy in $28.2 \%$ of cases, and nephropathy and neuropathy were observed, respectively, in $16.1 \%$ and $12.8 \%$ of our patients. Sixteen patients $(4.3 \%)$ had macrovascular complications of DM (coronary artery disease, peripheral arterial disease, and history of stroke) (Table 1).

3.2. Prevalence of Abnormalities. The total of patients with MS disorders was 129 (34.3\%) out of total 376 cases. They predominated among type 2 diabetics 119 (37.4\%) cases versus $10(17.2 \%)$ in type 1 diabetics. Hand disorders were seen in $54(14.4 \%)$ patients; CTS was the most prevalent $(8.8 \%)$ condition in $33(8.8 \%)$ patients $(28(8.8 \%)$ had T2DM versus $5(8.6 \%)$ with T1DM) followed by TF in $22(5.9 \%)$ patients (20 (6.3\%) had T2DM versus $2(3.4 \%)$ with T1DM) and LJM in 11 patients, and all of them had T2DM and DC in $2(0.5 \%)$ and all of them had T2DM. SC was present in $47(12.5 \%)$ patients (45 (14.2\%) had T2DM versus $2(3.4 \%)$ with T1DM) and CF in 1 case $(0.3 \%)$ with T1DM. OA was seen in $73(19.4 \%)$ patients $(71(38.4 \%)$ had T2DM versus 2 (22.2\%) with T1DM) (Table 2). Furthermore, One and two disorders were seen in $25.8 \%$ and $5.1 \%$ of our patients, respectively, while three disorders in the same patient were seen infrequently (3.5\%). The prevalence rates according to demographic and clinical characteristics of patients are shown in Table 3.

In the multivariate analysis, the only factors that were significantly associated with increased prevalence of one or more MS disorders were age above 50 years and dyslipidemia ( $P=0.002$ and $P=0.009$, respectively). Age above 50 years was an associated factor for SC and OA $(P=0.019$ and $P=0.010$, respectively). Duration of diabetes also seemed to confer higher risk; thus patients having diabetes for $>10$ years were more likely to have hand disorders $(p=0.017)$. Females were more likely to have OA $(P=0.009)$. Overweight and nephropathy seemed to be significantly associated with OA ( $P=0.004$ and $P=0.032$, respectively). Dyslipidemia was significantly associated with increased odds of hand disorders and SC ( $P=0.019$ and $P=0.047$, respectively) (Table 4).

\section{Discussion}

Many studies have evaluated MS disorders in diabetic patients, but most assessed only an individual component, especially upper limb MS abnormalities. Moreover, the relationship between dyslipidemia and MS disorders has been 
TABLE 1: Descriptive characteristics of the study population $(n=376)$.

\begin{tabular}{lc}
\hline & \\
\hline Age yrs; medians (IQR) & $54[45-62]$ \\
Gender & \\
$\quad$ Men n (\%) & $188(50)$ \\
$\quad$ Female n (\%) & $188(50)$ \\
Type of DM & \\
$\quad$ T1DM n (\%) & $58(15.4)$ \\
T2DM n (\%) & $318(84.6)$ \\
HbAlc; means (SD) & $8.5 \pm 1.9$ \\
BMI kg/m ${ }^{2}$; means (SD) & $26.4 \pm 3.6$ \\
Duration of DM yrs; medians (IQR) & $8[4-13]$ \\
Retinopathy n (\%) & $106(28.2)$ \\
Nephropathy n (\%) & $61(16.1)$ \\
Neuropathy $\mathbf{n}(\%)$ & $48(12.8)$ \\
Macrovascular complications n (\%) & $16(4.3)$ \\
Dyslipidemia n (\%) & $145(41)$ \\
\hline
\end{tabular}

DM: diabetes mellitus; T2DM: type 2 diabetes mellitus; T1DM: type 1 diabetes mellitus; HbAlc: hemoglobin Alc; BMI: body mass index.

TABLE 2: Prevalence and distribution of cases according to MS disorders in relation to type of diabetes.

\begin{tabular}{|c|c|c|c|c|c|c|c|}
\hline \multirow{4}{*}{ MS disorders } & \multicolumn{4}{|c|}{ Type of diabetes } & \multirow{4}{*}{$P$} & \multirow{3}{*}{\multicolumn{2}{|c|}{ Total $N=376$}} \\
\hline & \multirow{2}{*}{\multicolumn{2}{|c|}{$\begin{array}{l}\text { Type } 1 \\
\mathbf{N}=\mathbf{5 8}\end{array}$}} & \multirow{2}{*}{\multicolumn{2}{|c|}{$\begin{array}{c}\text { Type } 2 \\
\mathbf{N}=\mathbf{3 1 8}\end{array}$}} & & & \\
\hline & & & & & & & \\
\hline & $n$ & $\%$ & $n$ & $\%$ & & $n$ & $\%$ \\
\hline Osteoarthritis & 2 & 3.4 & 71 & 22.3 & $0.001^{*}$ & 73 & 19.4 \\
\hline Shoulder capsulitis & 2 & 3.4 & 45 & 14.2 & $0.023^{*}$ & 47 & 12.5 \\
\hline Carpel Tunnel Syndrome & 5 & 8.6 & 28 & 8.8 & 0.964 & 33 & 8.8 \\
\hline Limited joint mobility & 0 & 0 & 11 & 3.5 & 0.151 & 11 & 2.9 \\
\hline Trigger Finger & 2 & 3.4 & 20 & 6.3 & 0.397 & 22 & 5.9 \\
\hline Dupuytren's contracture & 0 & 0 & 2 & 0.6 & 0.545 & 2 & 0.5 \\
\hline Total MS disorders & 10 & 17.2 & 119 & 37.4 & 0.149 & 129 & 34.4 \\
\hline
\end{tabular}

MS: musculoskeletal.

neglected. The current study therefore examined various factors associated with increased prevalence of MS disorders in type 1 and $2 \mathrm{DM}$ including vascular complications and dyslipidemia.

Our study showed three important findings. First, the frequency of MS disorders in DM was $34.4 \%$. The most common MS complications were OA and hand disorders. Second, age above 50 years and dyslipidemia were significantly associated with the development of various MS manifestations. Third, $\mathrm{HgAlc}$ level was not found to be linked to any of MS disorders.

MS disorders (one or more) were seen in over one-third of our patients. In previous reports, the prevalence has been reported in about $36-75 \%$ of diabetic patients $[8,9]$. The lower prevalence of MS complications in our cohort could be related to the fact that we included type 1 and 2 DM. In our study, age above 50 years and dyslipidemia were observed to be associated with such disorders. These findings are similar to the results of previous studies $[10,11]$.

The prevalence of hand disorders is higher in patients with diabetes compared with nondiabetic subjects [10]. One or more hand disorders were seen in over $14.4 \%$ of our patients. In previous reports, the prevalence ranged between $26 \%$ and $64 \%[12,13]$. In our study, CTS was found in $8.8 \%$ followed by TF seen in $6.3 \%$ and LJM in $3.5 \%$ of patients. Duration of diabetes ( $\geq 10$ years) was observed to be associated with such disorders $(P=0.017)$. In fact, this association between the hand abnormality and the duration of diabetes is a consistent finding $[14,15]$. Moreover, we found a significant association between dyslipidemia and increased prevalence of hand disorders $(P=0.019)$.

The association between diabetes and SC is well established $[16,17]$. In our study, SC was found in $12.5 \%$. Prior studies reported variable prevalence rates of SC ranging between $11 \%$ and $19 \%$ in patients with diabetes, compared with $2 \%$ to $3 \%$ of age-matched controls [18]. In this study, older age and dyslipidemia have been linked to an increased risk of developing SC. Moreover, there was no association between HbAlc level and MS disorders. These findings are similar to the results of some previous studies $[10,19,20]$. Cagliero et al. reported a strong correlation between SC and microangiopathic complications [10]. Nevertheless, such association was not supported by our report. 
TABLE 3: Prevalence of MS disorders according to sociodemographics, vascular complications, and other relevant variables in diabetic patients.

\begin{tabular}{|c|c|c|c|c|}
\hline & $\begin{array}{c}\text { Hand disorders } \\
n(\%)\end{array}$ & $\begin{array}{l}\text { Shoulder Capsulitis } \\
n(\%)\end{array}$ & $\begin{array}{c}\text { Osteoarthritis } \\
n(\%)\end{array}$ & $\begin{array}{c}\text { MS disorders (total) } \\
n(\%)\end{array}$ \\
\hline \multicolumn{5}{|l|}{ Age (yrs) } \\
\hline$<50$ & $13(9.8)$ & $6(4.5)$ & $9(6.8)$ & $23(17.3)$ \\
\hline$\geq 50$ & $49(16.9)$ & $41(16.9)^{*}$ & $64(26.3)^{*}$ & $106(43.6)^{*}$ \\
\hline \multicolumn{5}{|l|}{ Gender } \\
\hline Male & $22(11.7)$ & $22(11.7)$ & $28(14.9)$ & $58(30.9)$ \\
\hline Female & $32(17)$ & $25(13.3)$ & $45(23.9)^{*}$ & $71(37.8)$ \\
\hline \multicolumn{5}{|l|}{ BMI (\%) } \\
\hline Normal & $15(10.3)$ & $15(10.3)$ & $15(10.3)$ & $38(26)$ \\
\hline overweight & $30(17.4)$ & $20(11.6)$ & $39(22.7)^{*}$ & $65(37.8)^{*}$ \\
\hline obesity & $9(15.5)$ & $12(20.7)$ & 19(32.8) & $26(44.8)^{*}$ \\
\hline \multicolumn{5}{|l|}{ Type DM } \\
\hline T1DM & $7(12.1)$ & $2(3.4)$ & $2(3.4)$ & $10(17.2)$ \\
\hline $\mathrm{T} 2 \mathrm{DM}$ & $47(14.8)$ & $45(14.2)^{*}$ & $71(22.3)^{*}$ & $119(37.4)^{*}$ \\
\hline \multicolumn{5}{|l|}{ Duration (yrs) } \\
\hline$<10$ & $20(9.9)$ & $23(11.4)$ & $29(14.4)$ & $53(26.2)$ \\
\hline$\geq 10$ & $34(19.5)^{*}$ & $24(13.8)$ & $44(25.3)^{*}$ & $76(43.7)^{*}$ \\
\hline \multicolumn{5}{|l|}{ HbAlc (\%) } \\
\hline$<7$ & $6(7.2)$ & $9(10.8)$ & $11(13.3)$ & $18(21.7)$ \\
\hline$\geq 7$ & $48(16.4)^{*}$ & $38(13)$ & $62(21.2)$ & $111(37.9)^{*}$ \\
\hline \multicolumn{5}{|l|}{ dyslipidemia } \\
\hline Yes & $30(20.1)^{*}$ & $27(18.1)^{*}$ & $42(28.2)^{*}$ & $70(47)^{*}$ \\
\hline Non & $24(10.6)$ & $20(8.8)$ & $31(13.7)$ & $59(26)$ \\
\hline \multicolumn{5}{|l|}{ Retinopathy } \\
\hline Yes & $16(15.1)$ & $15(14.2)$ & $31(29.2)^{*}$ & $49(46.2)^{*}$ \\
\hline Non & $38(14.1)$ & $32(11.9)$ & $42(15.6)$ & $80(29.6)$ \\
\hline \multicolumn{5}{|l|}{ Nephropathy } \\
\hline Yes & $8(13.1)$ & $11(18)$ & $21(34.4)^{*}$ & $28(45.9)^{*}$ \\
\hline Non & $46(14.6)$ & $36(11.4)$ & $52(16.5)$ & $101(32.1)$ \\
\hline \multicolumn{5}{|l|}{ Neuropathy } \\
\hline Yes & $11(22.9)$ & $6(12.5)$ & $11(22.9)$ & $24(50)^{*}$ \\
\hline Non & $43(13.1)$ & $41(12.5)$ & $62(18.9)$ & $105(32)$ \\
\hline \multicolumn{5}{|c|}{ Macrovascular disorder } \\
\hline Yes & $3(18.8)$ & $6(37.5)$ & $8(50)$ & $13(81.3)^{*}$ \\
\hline Non & $51(14.2)$ & $41(11.4)$ & $65(18.1)$ & $116(32.2)$ \\
\hline
\end{tabular}

${ }^{*} P<0.05 ; 95 \% \mathrm{CI}$

DM: diabetes mellitus; MS: musculoskeletal; T2DM: type 2 diabetes mellitus; T1DM: type 1 diabetes mellitus; HbAlc: hemoglobin Alc; BMI: body mass index.

The most frequent MS disorders in this study were OA, observed in 19.4\% of our patients. Most of them had T2DM. This association with T2DM can be partially explained by advanced age and high prevalence of overweight in this population. Hands, spine, and knees are the most common joints affected. We found that older age, female gender, and overweight were significantly associated with the presence of OA $(P=0.01, P=0.009$, and $P=0.004$, respectively). These findings were reported in previous study $[21,22]$. This relationship is not entirely clear; it has been traditionally attributed to underlying shared risk factors of age and obesity
$[23,24]$. The coexistence of both OA and DM can be a source of greater disability. In a population cohort with hip and knee $\mathrm{OA}$, Hawker et al. reported that one in six have diabetes. Among those with both OA and diabetes, baseline difficulty walking was a significant predictor of risk for serious diabetes complications [25]. In this study, we found that nephropathy was significantly associated with increased odds of OA $(P=$ 0.032).

Finally, this work has some possible limitations. It was an observational study and some additional confounders as smoking and physical activity were not included. 
TABLE 4: Multivariate analysis of factors associated with MS disorders.

\begin{tabular}{|c|c|c|c|c|c|c|c|c|}
\hline \multirow{2}{*}{ variable } & \multicolumn{2}{|c|}{ Hand disorders } & \multicolumn{2}{|c|}{ Shoulder capsulitis } & \multicolumn{2}{|c|}{ Osteoarthritis } & \multicolumn{2}{|c|}{ MS disorders (total) } \\
\hline & OR $(95 \% \mathrm{CI})$ & Pvalue & OR $(95 \% \mathrm{CI})$ & $P$ value & OR $(95 \% \mathrm{CI})$ & $P$ value & OR $(95 \% \mathrm{CI})$ & $P$ value \\
\hline \multicolumn{9}{|l|}{ Age (yrs) } \\
\hline$<50$ & & & 1 & & 1 & & 1 & \\
\hline$\geq 50$ & & & $\begin{array}{c}3.06 \\
(1.09-8.62)\end{array}$ & 0.019 & $\begin{array}{c}3.15 \\
(1.31-7.54)\end{array}$ & 0.010 & $\begin{array}{c}2.94 \\
(1.50-5.73)\end{array}$ & 0.002 \\
\hline \multicolumn{9}{|l|}{ Gender } \\
\hline Male & & & & & 1 & & & \\
\hline Female & & & & & $\begin{array}{c}2.15 \\
(1.20-3.85)\end{array}$ & 0.009 & & \\
\hline \multicolumn{9}{|l|}{ BMI (\%) } \\
\hline Normal & & & & & 1 & & & \\
\hline overweight & & & & & $\begin{array}{c}1.84 \\
(1.21-2.80)\end{array}$ & 0.004 & & \\
\hline obesity & & & & & $\begin{array}{c}0.6 \\
(0.3-1.15)\end{array}$ & 0.128 & & \\
\hline \multicolumn{9}{|l|}{ Duration (yrs) } \\
\hline$<10$ & 1 & & & & & & & \\
\hline$\geq 10$ & $\begin{array}{c}2.09 \\
(1.14-3.83)\end{array}$ & 0.017 & & & & & & \\
\hline \multicolumn{9}{|l|}{ Dyslipidemia } \\
\hline Non & 1 & & 1 & & & & 1 & \\
\hline Yes & $\begin{array}{c}2.03 \\
(1.12-3.68)\end{array}$ & 0.019 & $\begin{array}{c}1.90 \\
(1-3.59)\end{array}$ & 0.047 & & & $\begin{array}{c}1.89 \\
(1.17-3.06)\end{array}$ & 0.009 \\
\hline \multicolumn{9}{|l|}{ Nephropathy } \\
\hline Non & & & & & 1 & & & \\
\hline Yes & & & & & $\begin{array}{c}2.14 \\
(1.06-4.29)\end{array}$ & 0.032 & & \\
\hline
\end{tabular}

BMI: body mass index.

\section{Conclusion}

In the present study, MS disorders occur with a greater frequency in patients with DM. OA was the most frequently seen disorder. One or more MS disorders were significantly associated with various factors, especially dyslipidemia. Blood glucose control does not appear to be associated with development of MS disorders. We suggest that the MS examination should be included in the systematic evaluation of patients with diabetes.

\section{Data Availability}

The datasets generated during and/or analyzed during the current study are available from the corresponding author on reasonable request.

\section{Consent}

Written informed consent was obtained from patients for this study.

\section{Conflicts of Interest}

No conflicts of interest were declared by the authors.

\section{Acknowledgments}

Naima Benrachid contributed to the preparation of the manuscript.

\section{References}

[1] N. Cho, J. Shaw, S. Karuranga et al., "IDF Diabetes Atlas: Global estimates of diabetes prevalence for 2017 and projections for 2045," Diabetes Research and Clinical Practice, vol. 138, pp. 271281, 2018.

[2] M. Merashli, T. A. Chowdhury, and A. S. M. Jawad, "Musculoskeletal manifestations of diabetes mellitus," QJM: $A n$ International Journal of Medicine, vol. 108, no. 11, pp. 853-857, 2015.

[3] M. J. Mueller, "Musculoskeletal impairments are often unrecognized and underappreciated complications from diabetes," Physical Therapy in Sport, vol. 96, no. 12, pp. 1861-1864, 2016.

[4] J. C. Crispin and J. Alcocer-Varela, "Rheumatologic manifestations of diabetes mellitus," American Journal of Medicine, vol. 114, no. 9, pp. 753-757, 2003.

[5] M. Alikhani, Z. Alikhani, C. Boyd et al., "Advanced glycation end products stimulate osteoblast apoptosis via the MAP kinase and cytosolic apoptotic pathways," Bone, vol. 40, no. 2, pp. 345353, 2007. 
[6] Foundation $\mathrm{CH}$, “in Improving AGSP, Care for Elders with Diabetes C. Guidelines for improving the care of the older person with diabetes mellitus," Journal of the American Geriatrics Society, vol. 51, no. 5s, pp. 265-280, 2003.

[7] American Diabetes Association, "Standards of medical care in diabetes-2008," Diabetes Care, vol. 31, supplement 1, pp. S12S54, 2008.

[8] A. J. Mathew, J. B. Nair, and S. S. Pillai, "Rheumaticmusculoskeletal manifestations in type 2 diabetes mellitus patients in south India," International Journal of Rheumatic Diseases, vol. 14, no. 1, pp. 55-60, 2011.

[9] N. Ramchurn, C. Mashamba, E. Leitch et al., "Upper limb musculoskeletal abnormalities and poor metabolic control in diabetes," European Journal of Internal Medicine, vol. 20, no. 7, pp. 718-721, 2009.

[10] E. Cagliero, W. Apruzzese, G. S. Perlmutter, and D. M. Nathan, "Musculoskeletal disorders of the hand and shoulder in patients with diabetes mellitus," American Journal of Medicine, vol. 112, no. 6, pp. 487-490, 2002.

[11] S. M. Attar, "Musculoskeletal manifestations in diabetic patients at a tertiary center," Libyan Journal of Medicine, vol. 7, no. 1, 2012.

[12] S. Ravindran Rajendran, A. Bhansali, R. Walia, P. Dutta, V. Bansal, and G. Shanmugasundar, "Prevalence and pattern of hand soft-tissue changes in type 2 diabetes mellitus," Diabetes \& Metabolism, vol. 37, no. 4, pp. 312-317, 2011.

[13] M. Mota, C. Panuş, E. Mota et al., "Hand abnormalities of the patients with diabetes mellitus.", Romanian journal of internal medicine $=$ Revue roumaine de médecine interne, vol. 38-39, pp. 89-95, 2000.

[14] A. Gamstedt, J. Holm-Glad, C. G. Ohlson, and M. Sundström, "Hand abnormalities are strongly associated with the duration of diabetes mellitus," Journal of Internal Medicine, vol. 234, no. 2, pp. 189-193, 1993.

[15] K. N. Mustafa, Y. S. Khader, A. K. Bsoul, and K. Ajlouni, "Musculoskeletal disorders of the hand in type 2 diabetes mellitus: prevalence and its associated factors," International Journal of Rheumatic Diseases, vol. 19, no. 7, pp. 730-735, 2016.

[16] J. F. Bridgman, "Periarthritis of the shoulder and diabetes mellitus.," Annals of the Rheumatic Diseases, vol. 31, no. 1, pp. 69-71, 1972.

[17] S. J. Thomas, C. McDougall, I. D. M. Brown et al., "Prevalence of symptoms and signs of shoulder problems in people with diabetes mellitus," Journal of Shoulder and Elbow Surgery, vol. 16, no. 6, pp. 748-751, 2007.

[18] R. Spanheimer, "Skeletal and rheumatologic complications of diabetes," Therapeutic Advances in Endocrinology and Metabolism, vol. 4, pp. 55-80, 1993.

[19] P. E. T. Arkkila, I. M. Kantola, J. S. A. Viikari, and T. Rönnemaa, "Shoulder capsulitis in type I and II diabetic patients: Association with diabetic complications and related diseases," Annals of the Rheumatic Diseases, vol. 55, no. 12, pp. 907-914, 1996.

[20] Y. P. Huang, C. Y. Fann, Y. H. Chiu et al., "Association of diabetes mellitus with the risk of developing adhesive capsulitis of the shoulder: a longitudinal population-based followup study," Arthritis Care \& Research, vol. 65, no. 7, pp. 1197-1202, 2013.

[21] M. Nieves-Plaza, L. E. Castro-Santana, Y. M. Font, A. M. Mayor, and L. M. Vilá, "Association of hand or knee osteoarthritis with diabetes mellitus in a population of hispanics from puerto rico," JCR: Journal of Clinical Rheumatology, vol. 19, no. 1, pp. 1-6, 2013.

[22] K. G. Reeuwijk, M. De Rooij, G. M. Van Dijk, C. Veenhof, M. P. Steultjens, and J. Dekker, "Osteoarthritis of the hip or knee: Which coexisting disorders are disabling?" Clinical Rheumatology, vol. 29, no. 7, pp. 739-747, 2010.

[23] M. F. Williams, D. A. London, E. M. Husni, S. Navaneethan, and S. R. Kashyap, "Type 2 diabetes and osteoarthritis: A systematic review and meta-analysis," Journal of Diabetes and its Complications, vol. 30, no. 5, pp. 944-950, 2016.

[24] F. Berenbaum, "Diabetes-induced osteoarthritis: From a new paradigm to a new phenotype," Postgraduate Medical Journal, vol. 88, no. 1038, pp. 240-242, 2011.

[25] G. A. Hawker, R. Croxford, A. S. Bierman et al., "Osteoarthritisrelated difficulty walking and risk for diabetes complications," Osteoarthritis and Cartilage, vol. 25, no. 1, pp. 67-75, 2017. 


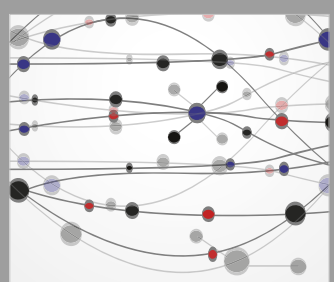

The Scientific World Journal
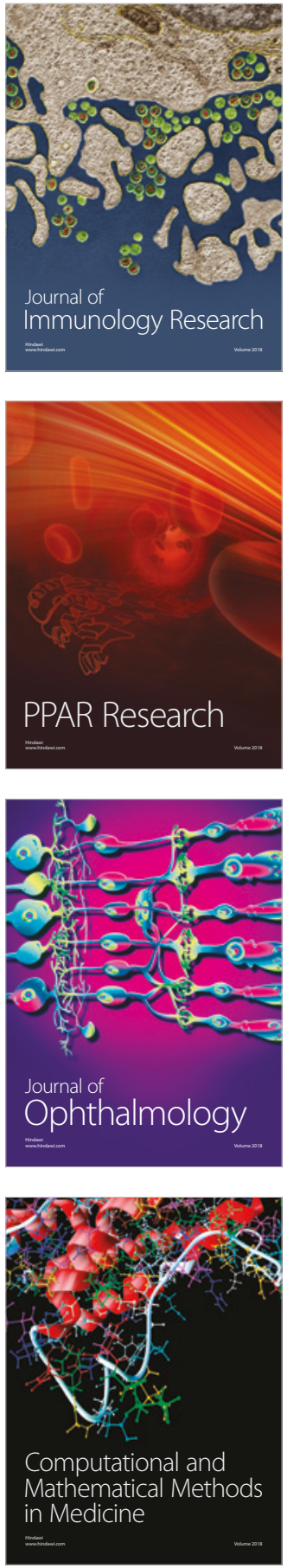

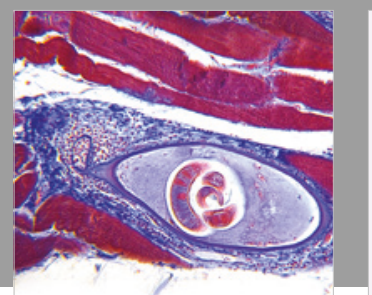

Gastroenterology Research and Practice

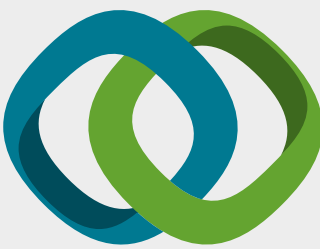

\section{Hindawi}

Submit your manuscripts at

www.hindawi.com
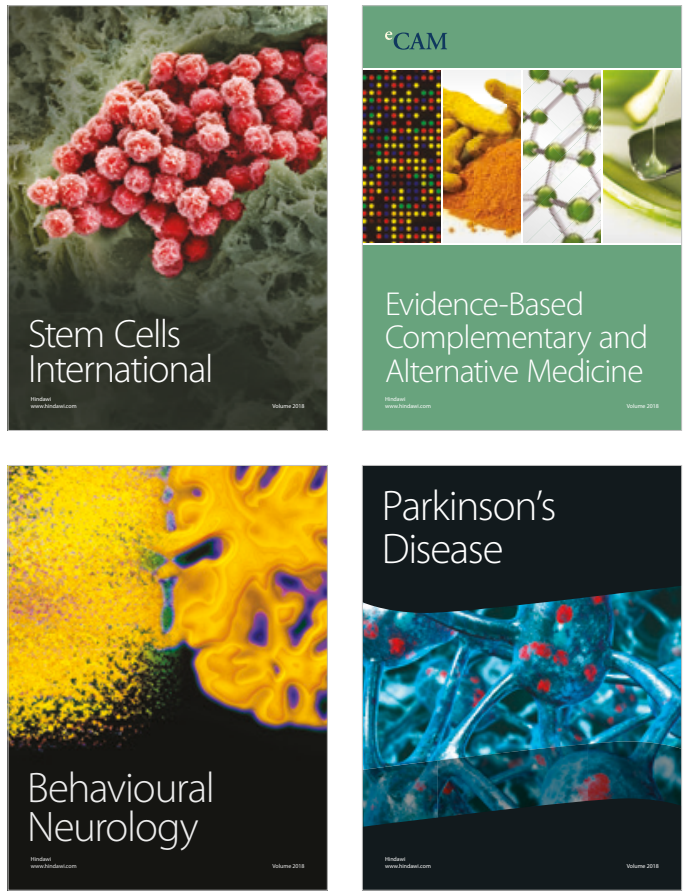

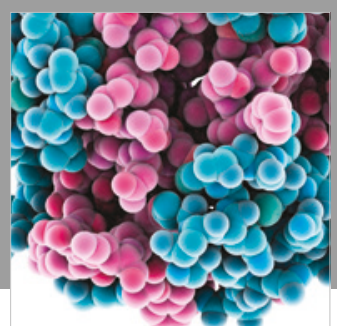

ournal of

Diabetes Research

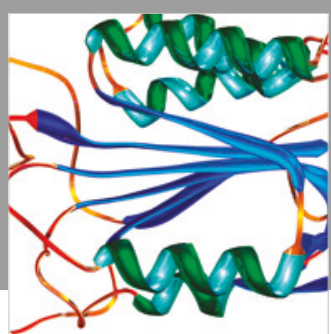

Disease Markers
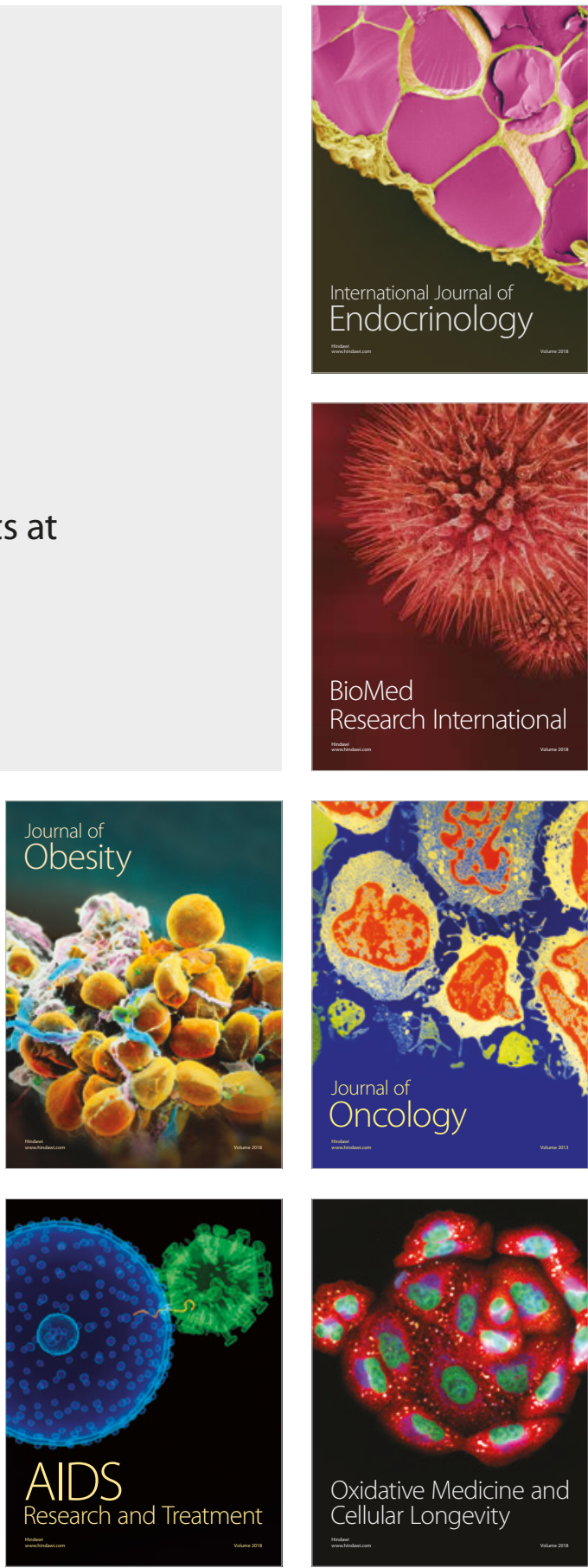